Article

\title{
Development and Application of a Cultivar-Specific Sequence-Characterized Amplified Region (SCAR) Marker for the Detection of Chrysanthemum morifolium Ramat. 'Daboju'
}

\author{
Yuchen Cai ${ }^{1,2}$, Yadi Gao ${ }^{1,2}$, Zhenhao Zhang ${ }^{1,2}$, Huijie Liu ${ }^{1}$, Yifan Wang ${ }^{1}$, Yuxin Ma ${ }^{1}$, Yixin Li ${ }^{1}$, \\ Shangguo Feng ${ }^{1,2, *}$ and Huizhong Wang ${ }^{1,2, *}$
}

check for updates

Citation: Cai, Y.; Gao, Y.; Zhang, Z.; Liu, H.; Wang, Y.; Ma, Y.; Li, Y.; Feng, S.; Wang, H. Development and Application of a Cultivar-Specific Sequence-Characterized Amplified Region (SCAR) Marker for the Detection of Chrysanthemum morifolium Ramat. 'Daboju'. Plants 2022, 11, 604. https://doi.org/ $10.3390 /$ plants11050604

Academic Editor: Adnane Boualem

Received: 29 December 2021

Accepted: 9 February 2022

Published: 24 February 2022

Publisher's Note: MDPI stays neutral with regard to jurisdictional claims in published maps and institutional affiliations.

Copyright: (C) 2022 by the authors. Licensee MDPI, Basel, Switzerland. This article is an open access article distributed under the terms and conditions of the Creative Commons Attribution (CC BY) license (https:// creativecommons.org/licenses/by/ $4.0 /)$.
1 College of Life and Environmental Science, Hangzhou Normal University, Hangzhou 310036, China; 2019111010003@stu.hznu.edu.cn (Y.C.); 2020111010014@stu.hznu.edu.cn (Y.G.); 2021111010013@stu.hznu.edu.cn (Z.Z.); liuhuijie@stu.hznu.edu.cn (H.L.); wangyifan@stu.hznu.edu.cn (Y.W.); myx@stu.hznu.edu.cn (Y.M.); liyixin@stu.hznu.edu.cn (Y.L.)

2 Zhejiang Provincial Key Laboratory for Genetic Improvement and Quality Control of Medicinal Plants, Hangzhou Normal University, Hangzhou 310036, China

* Correspondence: fsg008@hznu.edu.cn (S.F.); 20021157@hznu.edu.cn (H.W.)

\begin{abstract}
Chrysanthemum morifolium Ramat. 'Daboju' is a C. morifolium cultivar with important ornamental and medicinal values, and is often used in the treatment of colds, blurred vision, dizziness, and itchy skin. As the morphological characteristics of C. morifolium 'Daboju' are very similar to those of other C. morifolium cultivars, they are often confused in practice. However, the medicinal value and practical use of $C$. morifolium depends on using the correct rapid and accurate identification of C. morifolium 'Daboju' and its differentiation from other, morphologically similar C. $\times$ morifolium cultivars. Twenty-one polymorphic start codon-targeted (SCOT) primers were amplified in 21 distinct C. morifolium cultivars. One cultivar-specific DNA marker was developed with the aim of the rapid and accurate identification of $C$. morifolium 'Daboju' and its differentiation from other, similar C. morifolium cultivars. Twenty-one polymorphic start codon-targeted (SCoT) primers were amplified in 21 distinct $C$. morifolium cultivars. One cultivar-specific 385-bp amplicon (named SCoT36-385), amplified only in C. morifolium 'Daboju' (and in all samples of this cultivar), was identified, cloned, and sequenced. Subsequently, a sequence-characterized amplified region (SCAR) marker (named DBJF/DBJR), generating a 360-bp amplicon, was developed from SCoT36-385 and tested for amplification in all 21 C. morifolium cultivars, ten C. morifolium 'Daboju' populations, and different simulated adulterations of 'Daboju' with other cultivars. The primers amplified the specific 360-bp-long DNA fragment in all the tested C. morifolium 'Daboju' samples but failed in the absence of 'Daboju'. The detection limit of the SCAR primer pair (DBJF/DBJR) was $100 \mathrm{pg}$ of DNA extracted from C. morifolium 'Daboju'. Hence, this SCAR marker has a very high detection sensitivity, and can be used for accurate and rapid identification of $C$. morifolium 'Daboju'. It can play an important role in ensuring the quality of medicinal preparations and protecting C. morifolium 'Daboju' germplasm resources in breeding programs and in identifying lines generated from this cultivar.
\end{abstract}

Keywords: Chrysanthemum morifolium; cultivar identification; start codon-targeted polymorphism; sequence-characterized amplified region; marker development

\section{Introduction}

Chrysanthemum, Chrysanthemum morifolium Ramat., belongs to the family Asteraceae, and it has a long history of cultivation and use as a popular ornamental and herbal medicine use and cultivation in China, South Korea, Thailand, and Japan [1,2]. As a traditional medicinal plant, C. morifolium flowers have significant pharmacological effects for treating headaches, dizziness, sore carbuncles, swelling, poison, and cold or wind heat [3]. As growing conditions and processing methods vary between production areas, different 
regions produce different medicinal preparations. C. morifolium cultivars classified as 'Boju,' 'Chuju,' 'Gongju,' 'Hangju,' or 'Huaiju' types, based on origin and processing methods, are legal Chinese medicinal materials, according to the 2015 edition of the Pharmacopoeia of the People's Republic of China [3].

C. morifolium preparations are slightly cold in effect, with a sweet and bitter taste, with effects on wind, clearing heat, liver problems (ping mingmu tea), and for detoxification issues. Many studies have shown that the main active ingredients of chrysanthemum medicinal preparations include flavonoids, phenylpropanoids, and volatile oils, which have antiviral, anti-tumor, and anti-inflammatory effects [4-6]. Famous Chinese herbal medicine books, such as the 'Chinese Medicine Dictionary' and 'Chinese Materia Medica,' recorded that the 'Boju' type was the highest quality of medicinal chrysanthemum in China, and was mainly produced in Bozhou City, An'hui Province. In 2014, the Ministry of Agriculture of the People's Republic of China officially approved the registration and awarded the protection of agricultural products from 'Boju' under geographical indication [3].

However, despite the wide variety of chrysanthemum cultivars, the morphological characteristics of cultivars used in Traditional Chinese Medicine (TCM) are relatively similar; with the mutual introduction and cultivation of the same cultivars in different regions, the classification of chrysanthemum cultivars has become quite confused at present, and the problem of 'synonyms' and 'homonyms' is very serious [2,7]. Studies have shown that different accessions of medicinal chrysanthemum exhibited great differences in terms of biochemical quality, yield, and other aspects, and that their medicinal value was also very different [8-10]. For example, cultivars of the 'Boju' type are often used as a classical herbal tea to treat colds, blurred vision, dizziness, and itchy skin in TCM [11,12].

In recent years, C. morifolium 'Daboju,' as an important cultivar of the 'Boju' type, has attracted extensive interest due to its unique phenolic and volatile components, and its anti-inflammatory and anti-allergenic biological activities [3,11]. However, driven by economic interests, some unscrupulous merchants have used chrysanthemum varieties of poorer quality when marketing preparations of 'Daboju,' leading to chaos in the 'Daboju' market and inconsistent quality of chrysanthemum products, seriously affecting the healthy development of the 'Daboju' industry [13]. Therefore, to better protect and utilize 'Daboju' resources, it is of great importance that a rapid and accurate method for the identification and authentication of 'Daboju' be established, to distinguish it from material from other cultivars being passed off as 'Daboju'.

Initially, morphological [14,15], cellular [16], and biochemical markers [12,17] were often used as the major detection methods to distinguish different chrysanthemum cultivars. All these methods are difficult to operate, and are susceptible to environmental and developmental factors, and to plant sample adulteration. For example, some systems classify chrysanthemums according to their flower color, shape, or flowering period, but the use of all of these are restricted to the flowering stage of plant development. In contrast, the use of DNA molecular markers is an efficient and low-cost method for plant identification, and one that is independent of environmental and physiological conditions [18,19]. To date, many DNA molecular markers, including randomly amplified polymorphic DNA (RAPD), amplified fragment length polymorphism (AFLP), inter-simple sequence repeat (ISSR), sequence-related amplified polymorphism (SRAP), and simple sequence repeat (SSR), have been used widely used in genetic diversity assessment [20-22], phylogenetic analysis [23], genetic linkage map construction [24], QTL mapping [25,26], and phenotypic trait association analysis [27] of chrysanthemum germplasm resources. However, a number of studies have shown that the direct application of these markers to the molecular identification of plants is not ideal [28-30]. Sequence-characterized amplified region (SCAR), a class of reliable PCR-based DNA molecular marker, has been developed from a specific nucleotide sequence generated by certain traditional molecular markers, such as RAPDs, ISSRs, and AFLPs [31-33]. SCAR markers have been widely used in the molecular identification of plant species, cultivars, or traditional medicinal preparations due to their high stability and specificity, simple operation, and low cost [28,30,34-37]. 
In the present study, we developed a useful SCAR marker for 'Daboju' identification via the use of start codon-targeted (SCOT) primers, which are PCR-based gene-targeted markers, in which the SCOT primers are based on conserved regions flanking the translation start codon of genes [38]. At the same time, we established a sensitive and simple PCRbased method for the rapid molecular identification of 'Daboju' and its differentiation from other, closely related chrysanthemum cultivars.

\section{Results}

\subsection{SCoT Analysis and Specific Locus Identification}

After the initial primer screening, a total of 21 SCoT primers, each generating clear and repeatable polymorphic patterns, were selected for further study (Table 1). The 21 SCoT primers generated 187 reliable loci with a range of 5-13 loci amplified by each primer, with an average of 8.90 loci per primer. Of these, 163 loci $(87.17 \%)$ were polymorphic, ranging from 4 to 12 loci amplified per primer, with an average of 7.76 loci per primer. The percentage of polymorphic bands generated by each primer varied from $66.7 \%$ to $100.0 \%$, with an average of $85.70 \%$. Among the 163 polymorphic loci, only one amplicon (385-bp-long), amplified by primer SCoT36, was found to be present in the 'Daboju' sample but was absent from samples of all the other cultivars (Figure 1), which could therefore potentially be used for rapid and accurate molecular identification of 'Daboju' and the development of a specific SCAR marker specific for 'Daboju'.

Table 1. Sequences and polymorphism information of the 21 SCoT primers.

\begin{tabular}{|c|c|c|c|c|c|}
\hline Primer Code & Primer Sequence $\left(5^{\prime}-3^{\prime}\right)$ & $\begin{array}{l}\text { Working Annealing } \\
\text { Temperature }\left({ }^{\circ} \mathrm{C}\right)\end{array}$ & No. of Amplified Loci & No. of Polymorphic Loci & Polymorphic Loci (\%) \\
\hline SCoT1 & CAACAATGGCTACCACCA & 50 & 13 & 10 & 77.00 \\
\hline SCoT2 & CAACAATGGCTACCACСC & 52 & 12 & 12 & 100.00 \\
\hline SCoT3 & CAACAATGGCTACCACCG & 52 & 11 & 11 & 100.00 \\
\hline SCoT4 & CAACAATGGCTACCACCT & 50 & 7 & 6 & 85.70 \\
\hline SCoT5 & CAACAATGGCTACCACGA & 50 & 9 & 8 & 88.90 \\
\hline SCoT11 & AAGCAATGGCTACCACCA & 52 & 8 & 7 & 87.50 \\
\hline SCoT12 & ACGACATGGCGACCAACG & 56 & 7 & 5 & 71.40 \\
\hline SCoT16 & ACCATGGCTACCACCGAC & 54 & 9 & 8 & 88.90 \\
\hline SCoT19 & ACCATGGCTACCACCGGC & 57 & 10 & 8 & 80.00 \\
\hline SCoT20 & ACCATGGCTACCACCGCG & 58 & 10 & 9 & 90.00 \\
\hline SCoT21 & ACGACATGGCGACCCACA & 57 & 7 & 5 & 71.40 \\
\hline SCoT22 & AACCATGGCTACCACCAC & 52 & 6 & 4 & 66.70 \\
\hline SCoT23 & CACCATGGCTACCACCAG & 53 & 5 & 4 & 80.00 \\
\hline SCoT24 & CACCATGGCTACCACCAT & 52 & 9 & 9 & 100.00 \\
\hline SCoT26 & ACCATGGCTACCACCGTC & 54 & 10 & 9 & 90.00 \\
\hline SCoT30 & CCATGGCTACCACCGGCG & 60 & 10 & 10 & 100.00 \\
\hline SCoT32 & CCATGGCTACCACCGCAC & 56 & 10 & 9 & 90.00 \\
\hline SCoT33 & CCATGGCTACCACCGCAG & 56 & 7 & 6 & 85.70 \\
\hline SCoT34 & ACCATGGCTACCACCGCA & 56 & 7 & 5 & 71.40 \\
\hline SCoT35 & CATGGCTACCACCGGCCC & 58 & 12 & 12 & 100.00 \\
\hline SCoT36 & GCAACAATGGCTACCACC & 52 & 8 & 6 & 75.00 \\
\hline Average & - & - & 8.90 & 7.76 & 85.70 \\
\hline Total & - & - & 187 & 163 & - \\
\hline
\end{tabular}

\subsection{Sequence Analysis and SCAR Marker Development}

The 385-bp amplicon specific to 'Daboju,' named SCOT36-385, was cloned, sequenced, and deposited in GenBank (GenBank accession number: OL456174). The specific nucleotide sequence of SCoT36-385 consisted of $63.12 \% \mathrm{~A}+\mathrm{T}$ and $36.88 \% \mathrm{G}+\mathrm{C}$, as shown in Figure 2. The BLASTN of the SCOT36-385 sequence did not show a similarity with other sequences in the GenBank database, and no repeats were detected. This 'Daboju'-discriminating SCoT band was subsequently converted into a SCAR marker (primer pair named DBJF/DBJR) (Figure 2 and Table 2). The lengths of the forward and reverse primers for the SCAR marker DBJF/DBJR were 18- and 18-mer, respectively. 


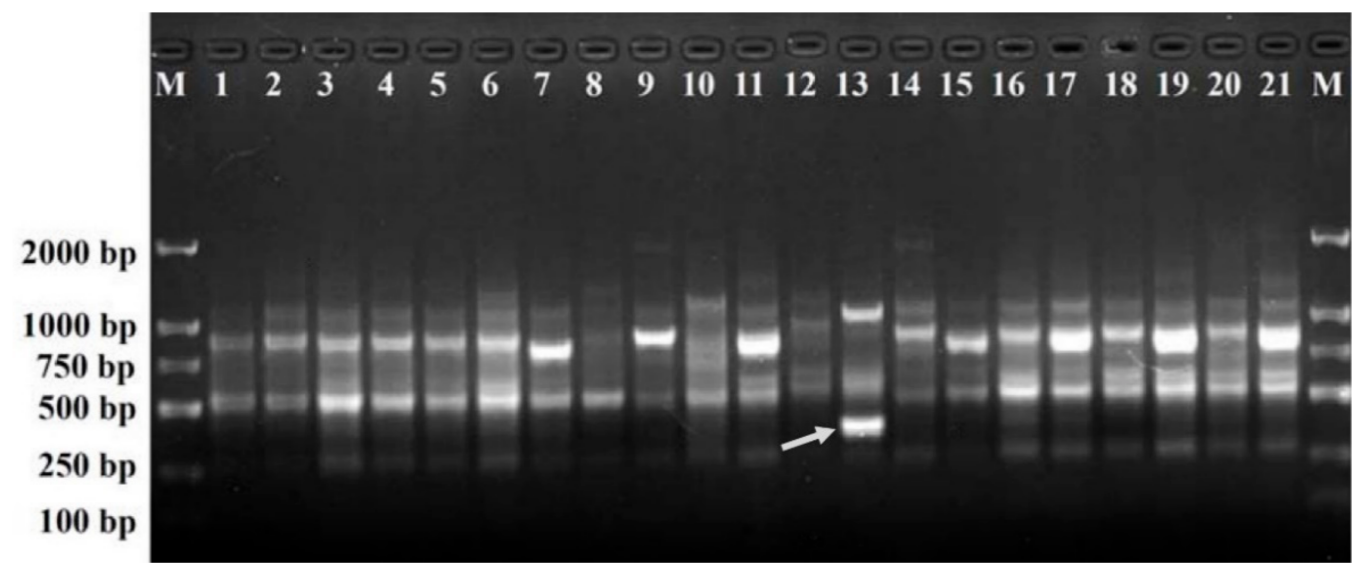

Figure 1. SCoT36 profiles of the 21 different C. morifolium cultivars (lanes 1-21). Lane M: Trans2K DNA markers with specified amplified product lengths (bp). Arrowheads represent specific amplified band in the C. morifolium 'Daboju' sample.

DBJF

GCAACAATGGCTACCACCCAGGGAGGATTGAATTCAAAGTTTTGACA

TTTAGAAGCGATAAATATAGTTCCCTTAGAACCACCAGGACATAAGCGT

GACGGCGTCATTAGCTTAGACCAGTTTTACTGTCTGTCTATTTGTACAA

CAGAAAATCATTTGGTATTCAACTAGTAATTATGAATATGAATGCATGGA

ATAGAAGGGAAAAAAAGACTAATACCCACCACAATTTTGTGATCATTG

ATATAGTACTCAAAAGCATGACTTTTGTATTGACACTATCGGAAAATCTG

CAACTGGAATTGAAGCATCTAAGATGAAAGGAGCTAATAATAGCATGTC

\section{AACTGACAATTAACATGCCTTACAAGGTGGTAGCCATTGTTGC DBJR}

Figure 2. Nucleotide sequence of the SCoT marker specific to C. morifolium 'Daboju'. The sequence was named SCOT36-360 and has been deposited in GenBank (Accession number: OL456174). The underlined bold sequences represent the forward primer (DBJF) and the reverse primer (DBJR).

Table 2. Characteristics of the cultivar-specific SCAR primer pair derived from the cloned SCoT36derived amplicon of $C$. morifolium 'Daboju'.

\begin{tabular}{clcccc}
\hline SCAR Primer & $\begin{array}{c}\text { SCAR Primer } \\
\text { Sequence }\left(5^{\prime}-\mathbf{3}^{\prime}\right)\end{array}$ & Length & GC Content (\%) & $\begin{array}{c}\text { Working Annealing } \\
\text { Temperature }\left({ }^{\circ} \mathbf{C}\right)\end{array}$ & Amplicon Length (bp) \\
\hline DBJF & ACCACCCAGGGAGGATTG & 18 & 61.11 & 62 \\
DBJR & CCACCTTGTAAGGCATGT & 18 & 50.00 & 360 \\
\hline
\end{tabular}

\subsection{Amplification of the Designed SCAR Primers Designed}

The designed SCAR primer pair DBJF/DBJR was then used to amplify genomic DNA from the 21 chrysanthemum cultivars at the optimum annealing temperature of $62{ }^{\circ} \mathrm{C}$ to evaluate the specificity of amplification. The amplification profile of the primer pair DBJF/DBJR is shown in Figure 3. The results showed that a clear, specific amplicon of $360 \mathrm{bp}$ was generated from the 'Daboju' DNA samples by the primer pair, but no amplicons were detected from DNA samples from any of the other 20 chrysanthemum cultivars. The SCAR primer pair DBJF/DBJR did not contain the sequence of the original SCoT primer, thus giving rise to amplification products shorter than the original selected sequence, which should increase the specificity of amplification. Furthermore, the stability and specificity 
of the SCAR primer pair DBJF/DBJR were further validated in different DNA samples from ten 'Daboju' populations. The results showed the specific amplicon of the primer pair DBJF/DBJR at 360 bp with all ten samples confirming the identity of all ten 'Daboju' populations (Figure 4).
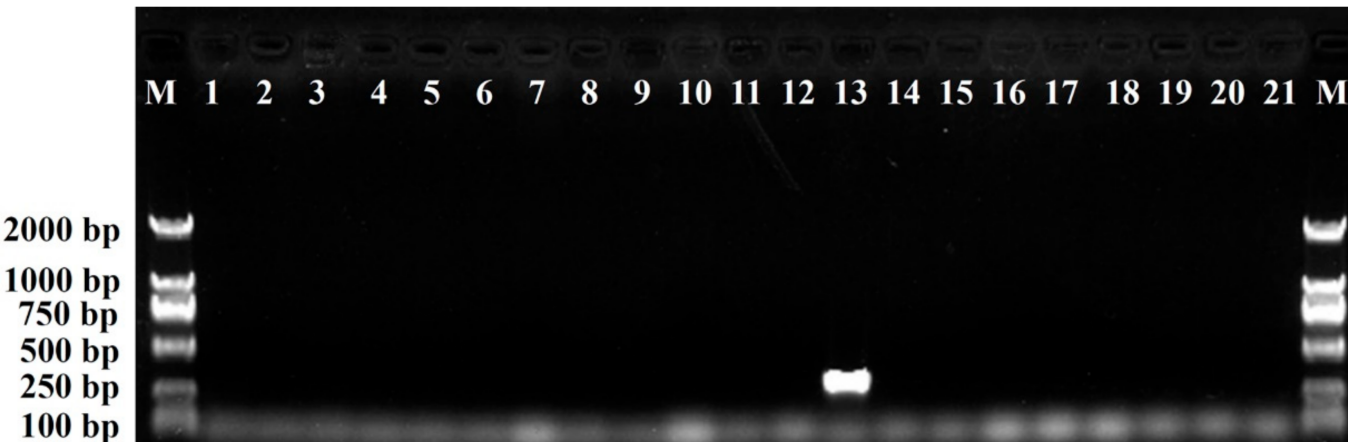

Figure 3. Amplification of the SCAR marker DBJF/DBJR primer pair developed in the genomic DNA of the 21 different $C$. morifolium cultivars (lanes 1-21). Lane M: Trans2K DNA marker with specified amplification product lengths (bp). A specific amplified band of 360-bp length was detected in the C. morifolium 'Daboju' sample.

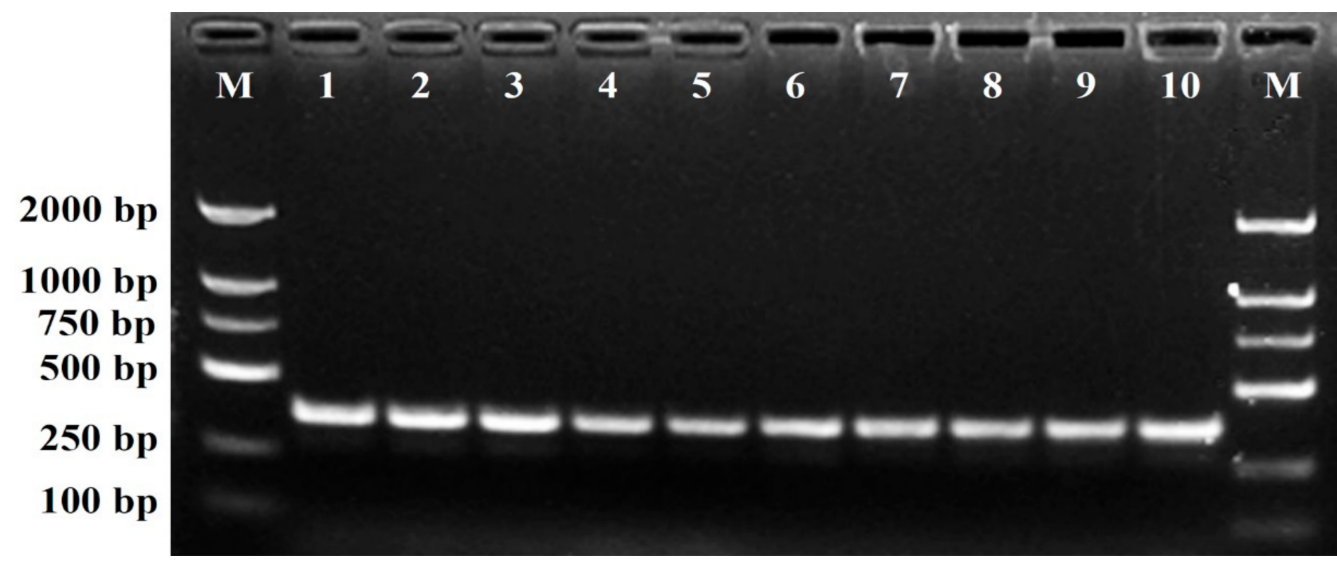

Figure 4. Amplification profiles of the primer pair DBJF/DBJR in the ten C. morifolium 'Daboju' samples (lanes 1-10). Lane M: Trans2K DNA marker with specified amplification product lengths (bp). The specific amplified bands of 360-bp length were detected in all the C. morifolium 'Daboju' individuals.

\subsection{Sensitivity and Application of the Specific SCAR Marker}

The sensitivity of the SCAR marker DBJF/DBJR was evaluated using a dilution series of 'Daboju' genomic DNA samples. The results suggested that the sensitivity limit of the primers DBJF/DBJR was 100 pg of genomic DNA in the $20 \mu \mathrm{L}$ PCR reaction mixture (Figure 5). Furthermore, the different simulated adulterations of 'Daboju' with tissue from other cultivars showed that only the simulated adulterated samples containing 'Daboju' tissue generated the 360-bp amplicon using the primers DBJF/DBJR, whereas this amplicon was not found in the adulterated samples of 'Xiaoyangju,' 'Zaoxiaoyangju,' 'Dayangju,' 'Machengju,' and 'Hongxinju' without 'Daboju' (Figure 6). Therefore, the SCAR marker DBJF/DBJR has been demonstrated to represent an effective tool with simple operation, high accuracy and sensitivity, and low economic cost to identify whether 'Daboju' was present in Chinese herbal medicinal materials for clinical applications. 


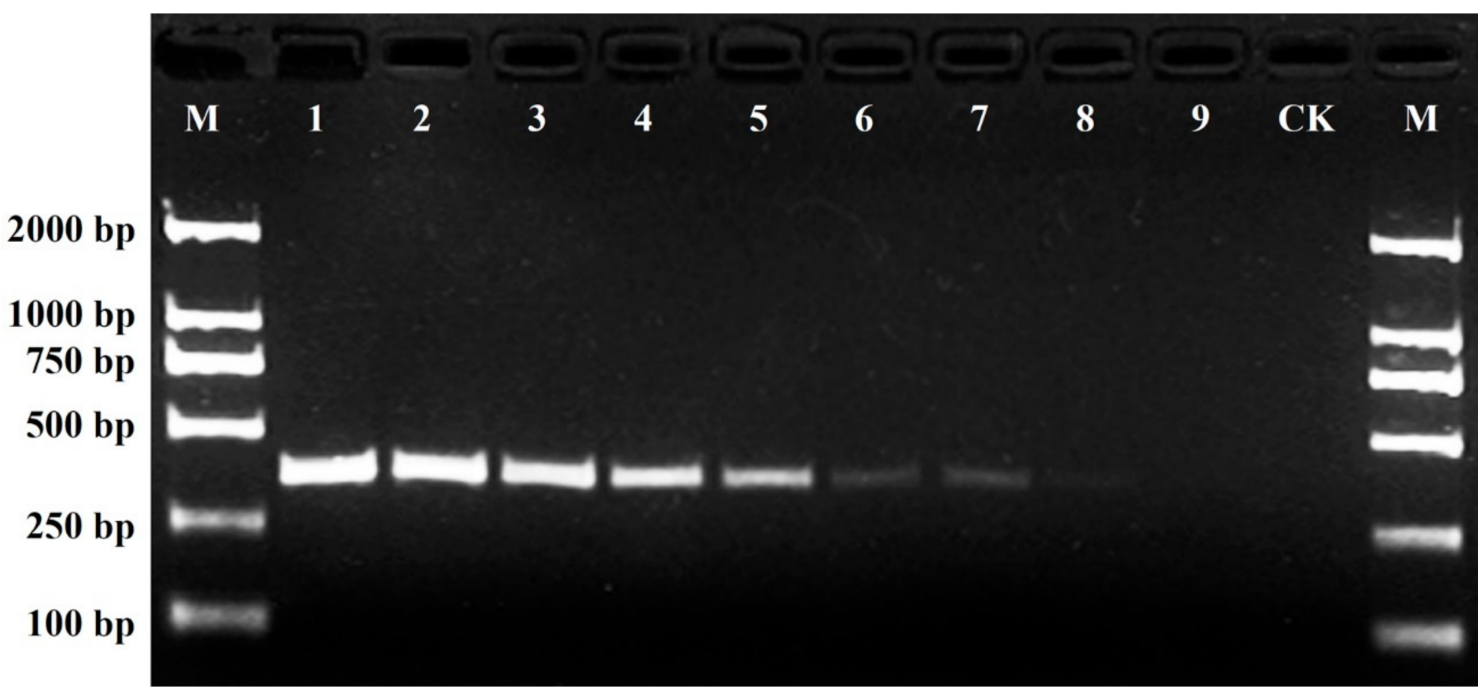

Figure 5. The sensitivity of the SCAR markers (DBJF/DBJR) with different $C$. morifolium 'Daboju' genomic DNA concentrations in a $20 \mu \mathrm{L}$ PCR mixture. Lane M: Trans2K DNA Marker with specified amplification product band lengths (bp); lanes 1-9: $50 \mathrm{ng} / \mu \mathrm{L}, 40 \mathrm{ng} / \mu \mathrm{L}, 30 \mathrm{ng} / \mu \mathrm{L}, 20 \mathrm{ng} / \mu \mathrm{L}$, $10 \mathrm{ng} / \mu \mathrm{L}, 5 \mathrm{ng} / \mu \mathrm{L}, 1 \mathrm{ng} / \mu \mathrm{L}, 100 \mathrm{pg} / \mu \mathrm{L}$, and $10 \mathrm{pg} / \mu \mathrm{L}$, respectively; lane $\mathrm{CK}: \mathrm{ddH}_{2} \mathrm{O}$, instead of the DNA template of C. morifolium 'Daboju'.

Table 3. Simulated adulteration samples used for SCAR marker DBJF/DBJR application.

\begin{tabular}{|c|c|c|c|c|c|c|}
\hline \multirow{2}{*}{ Num. } & \multicolumn{5}{|c|}{ Different Incorporation Ratios of Chrysanthemum Varieties (\%) } & \multirow{2}{*}{$\begin{array}{l}\text { The Total Proportion of Non-'Daboju' } \\
\text { Chrysanthemum Variety Adulteration (\%) }\end{array}$} \\
\hline & 'Daboju' & 'Xiaoyangju' & 'Zaoxiaoyangju' ‘Dayangju' & 'Machengju' & 'Hongxinju' & \\
\hline 1 & 100 & & & & & 0 \\
\hline 2 & 50 & 50 & & & & 50 \\
\hline 3 & 33.3 & 33.3 & 33.3 & & & 67 \\
\hline 4 & 25 & 25 & 25 & & & 75 \\
\hline 5 & 20 & 20 & 20 & 20 & & 80 \\
\hline 6 & 0 & 20 & 20 & 20 & 20 & 100 \\
\hline
\end{tabular}

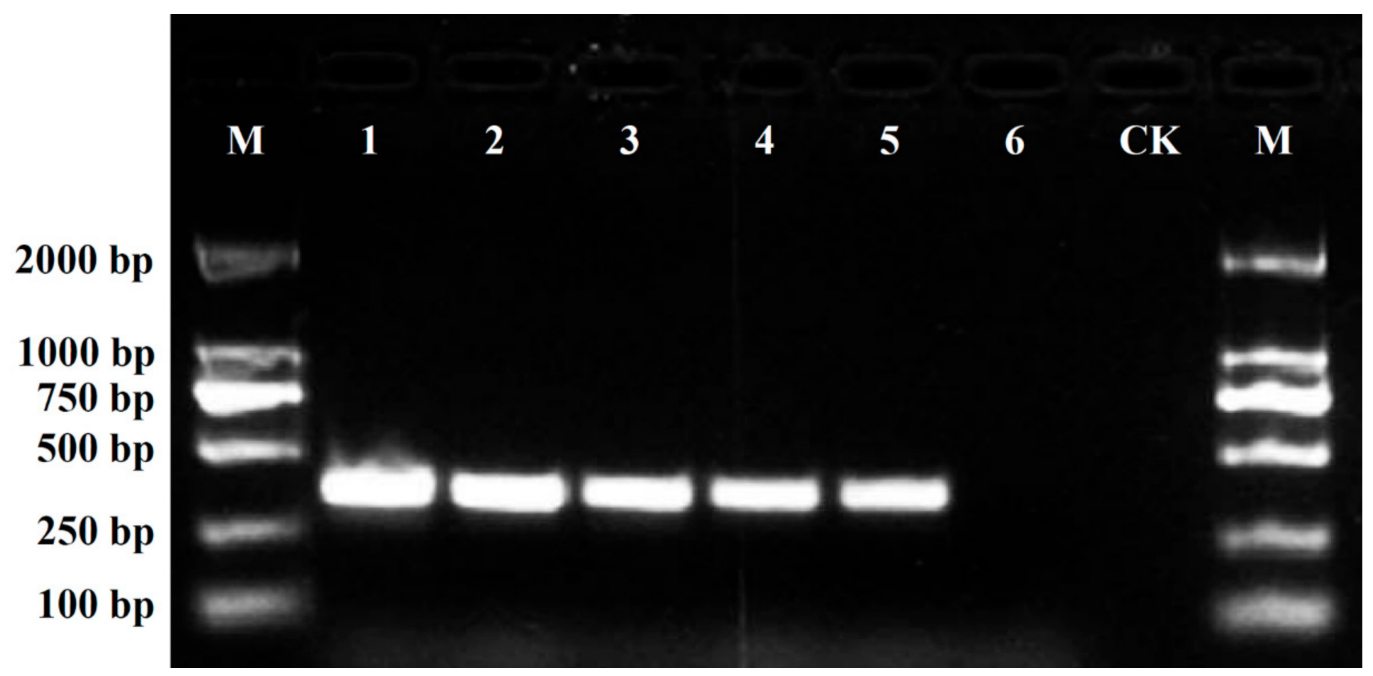

Figure 6. Amplification profiles of the primer pair DBJF/DBJR in genomic DNA composed of different combinations of $C$. morifolium cultivars. Lane M: Trans2K DNA markers with specified amplification product band lengths (bp); lanes 1-6: different proportions of adulteration of C. morifolium cultivars, with details of the adulterations provided in Table 3; lane CK: $\mathrm{ddH}_{2} \mathrm{O}$, instead of the DNA template of C. morifolium cultivars. 


\section{Discussion}

Accurate identification of plant cultivars is an important part of plant product quality control, especially in situations where suppliers may be intentionally providing material from the wrong cultivars [39]. 'Daboju,' one of the chrysanthemum cultivars with ornamental and medicinal use, occupies a prominent position in horticulture and TCM thanks to the important ornamental and medicinal values of its flowers. Substitution or adulteration of 'Daboju' preparations might damage the effectiveness of TCM treatments and even endanger the safety of consumers. Nevertheless, 'Daboju' and other medicinal chrysanthemum cultivars are very similar in terms of flower appearance and shape. As 'chrysanthemum' is an umbrella term for many different chrysanthemum cultivars, which are very similar in appearance and closely related, accidental or deliberate adulteration or mislabeling is highly possible. Although different chrysanthemum cultivars can be distinguished by very subtle differences in flower morphology or color, chrysanthemums only bloom once a year under most climatic conditions. Hence, it is difficult to confirm the identity of these chrysanthemum cultivars quickly and accurately by traditional morphometric methods. Therefore, identification using qualitative molecular markers will contribute to our ability to identify chrysanthemum plants at any stage of development.

Up to now, many types of molecular markers, including RAPD, AFLP, SSR, ISSR, SRAP, and SCoT, have been used for genetic diversity evaluation, genetic relationship analysis, genetic map construction, and trait correlation analysis of chrysanthemum germplasm resources $[10,22,24,26,40,41]$. Although these DNA molecular markers have a wide range of applications for the DNA analysis of plants, their lack of reproducibility makes them unreliable for direct, rapid, and unequivocal identification of plant cultivars.

To overcome these shortcomings, the SCAR marker, a more specific type of marker, was developed. SCAR markers have been widely used in the identification of cultivars, species, substitutes, and adulterants because they are specific to single loci and their PCR amplification is relatively insensitive to reaction conditions. Traditional DNA molecular markers, such as RAPD, ISSR, AFLP, SRAP, and SSR, can be transformed into SCAR markers based on sequence data, a process that improves the reproducibility of the PCR products of SCAR markers. In the present study, a specific SCAR marker was developed for the authentication of 'Daboju,' based on SCoT analysis. In recent years, SCAR markers have increasingly been used for the authentication of medicinal plants, such as Ocimum tenuiflorum [33], Trapa natans [42], Lycium chinense [43], and Dendrobium officinale [36]. In addition, SCAR markers have also been used to identify adulterants in commercially important plantderived food and medicinal products, such as Crocus sativus [44], Aconitum heterophyllum and Cyperus rotundus [37], Punica granatum [30], and Panax ginseng [45].

As a molecular marker technique, generating high levels of polymorphism and capable of high stability, the recent introduction of SCoT markers has been widely welcomed in recent years [29]. Some SCAR markers, converted from SCoT primers, have been used for the identification of a number of plants $[29,39,46,47]$. In the present study, a specific 385-bp DNA sequence (SCoT36-385) was amplified by SCoT36, which could be used to identify 'Daboju' samples after being converted into a SCAR marker. In order to increase the stability and specificity of the amplification product, the sequence size of the PCR product amplified by SCAR primers was made slightly shorter than that of the original specific DNA fragment $[29,30]$. In this study, the specific band size obtained by the SCAR primers DBJF/DBJR was $360 \mathrm{bp}$, which was 25-bp shorter than the original specific SCoT sequence, SCoT36-385 (385 bp in length).

There are many cultivars of medicinal chrysanthemum, and the specific uses and medicinal values of different cultivars also vary. In order to ensure the clinical safety and effectiveness of preparations of chrysanthemum 'Daboju,' genuine raw material of 'Daboju' must be used. Therefore, it is necessary to establish a rapid, inexpensive, efficient, and accurate method by which to identify chrysanthemum 'Daboju' and distinguish it from other cultivars or from adulterated preparations. In recent years, DNA barcoding has gained popularity in species identification [48-51]. Its advantage is that the target 
sequence comes from a known region of the genome, which helps in evolutionary studies. However, DNA barcoding also has its disadvantages. For example, DNA barcoding requires the sequencing of every individual, which is expensive and time-consuming. Furthermore, DNA barcoding has a low success rate in distinguishing between cultivars. In contrast, SCAR marker technology is cheaper and takes less time than barcoding, and its specific primers are relatively easy to design. More importantly, SCAR marker primers are less affected by the external environment, and they have a very high success rate in the identification of interspecific, intraspecific, and adulterated products [30,39]. The SCAR marker primer pair DBJF/DBJR developed here could amplify specific DNA fragments of a certain length in 'Daboju' samples, whereas no DNA bands were amplified in samples of other chrysanthemum cultivars in the absence of a threshold concentration (100 pg DNA $/ 20 \mu \mathrm{L}$ ) of 'Daboju'. This finding showed that the SCAR primer pair DBJF/DBJR could be used for the identification of 'Daboju' and its distinction from other, similar chrysanthemum cultivars. Our results showed that the SCAR primer pair DBJF/DBJR could detect $100 \mathrm{pg}$ of the 'Daboju' DNA template in a $20 \mu \mathrm{L}$ PCR reaction mixture, which indicated that the identification sensitivity of DBJF/DBJR was very high, with only a small amount of sample DNA being needed to achieve rapid and accurate identification of 'Daboju'. The development of cultivar-specific SCAR markers is more difficult than that of species-specific SCAR markers due to the closer genetic relationship between cultivars. It can be said that the cultivar-specific SCAR markers are complex to develop, requiring a large amount of work in screening, sequencing, design, and verification. However, once the SCAR marker is developed successfully, it is of great application value and significance with respect to its practical application.

\section{Materials and Methods}

\subsection{Plant Materials}

Twenty-one chrysanthemum cultivars, including 'Jinju 1,' 'Jinju 2,' 'Jinju 3,' 'Xiaoyangju,' 'Zaoxiaoyangju,' 'Dayangju, ' Yizhongdabaiju,' 'Xiaohuangju,' 'Huangyaoju,' 'Jiuyueju,' 'Zhaohua 1,' 'Jinsihuangju,' 'Daboju, 'Zaogongju,' 'Wuyuanhuangju,' 'Xiaobaiju,' 'Machengju,' 'Dahuangju,' 'Hongxinju,'Changbanju,' and 'Dabaiju,' were collected from their main cultivation areas (Figure 7) for SCoT analysis by pooling fresh leaves from at least six individuals of each cultivar (Table 4). These plant materials were preserved and cultivated at the Tongxiang Chrysanthemum Experimental Field of the Zhejiang Provincial Key Laboratory for Genetic Improvement and Quality Control of Medicinal Plants, Hangzhou Normal University, Zhejiang Province, China. Voucher samples were deposited at the Zhejiang Provincial Key Laboratory for Genetic Improvement and Quality Control of Medicinal Plants. Relevant morphological features of flowers of samples are shown inFigure 8, respectively. In addition, tissue samples from 10 'Daboju' populations (Table 5) collected from Zhejiang and An'hui provinces (Figure 9) were selected for validating the SCAR marker, using fresh leaves pooled from at least eight individuals of each population.

\subsection{DNA Extraction}

Total genomic DNA preparations were extracted after pooling fresh leaves from six or more different individuals of each cultivar, using the Plant Genomic DNA Extraction Kit (Shanghai Sangon Biological Engineering Technology and Service Co. Ltd., Shanghai, China). The integrity and quality of the DNA preparations were evaluated by electrophoresis on $1.0 \%(w / v)$ agarose gel, and the concentration of DNA was determined using a UV spectrophotometer. 


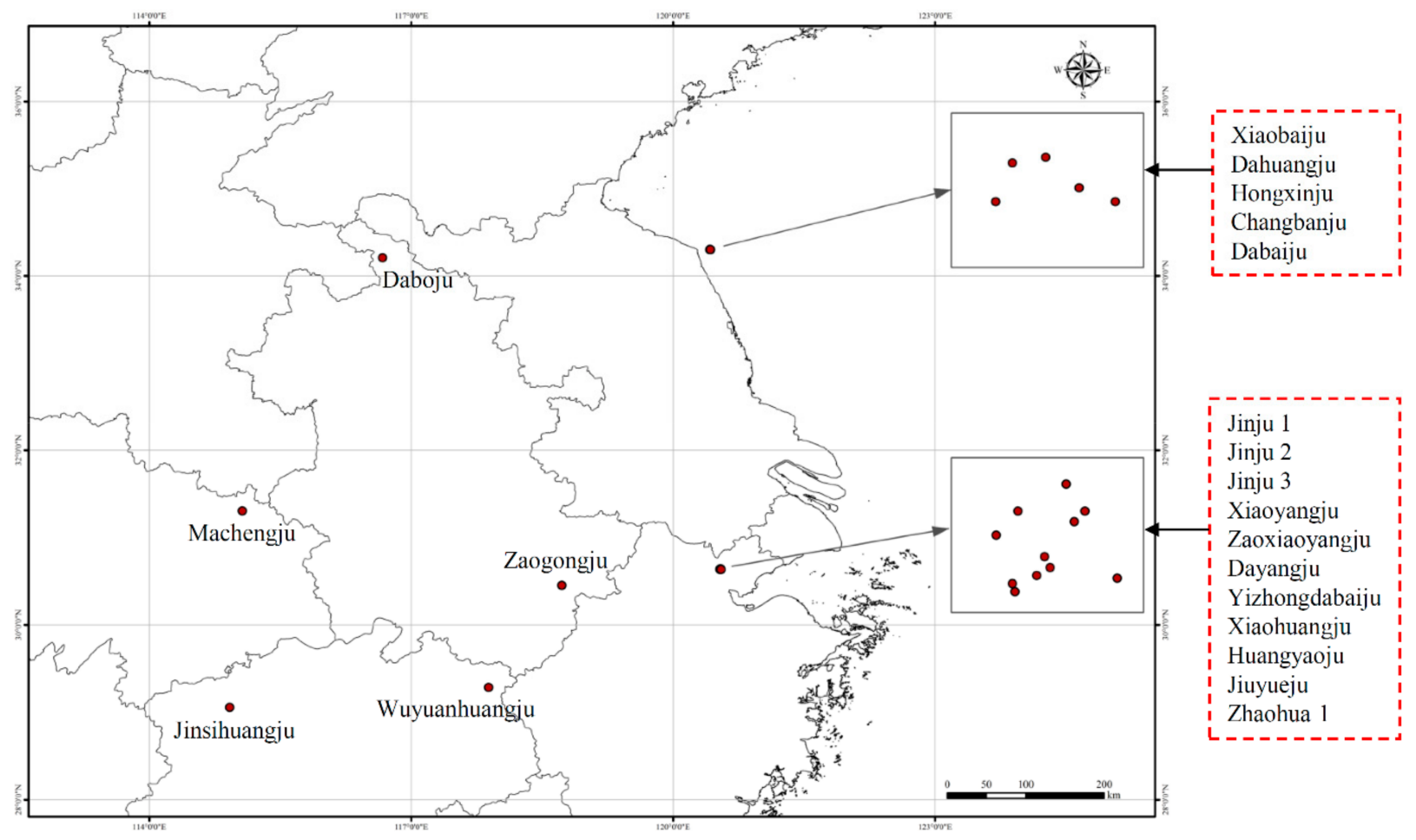

Figure 7. Sampling locations of 21 C. morifolium cultivars.

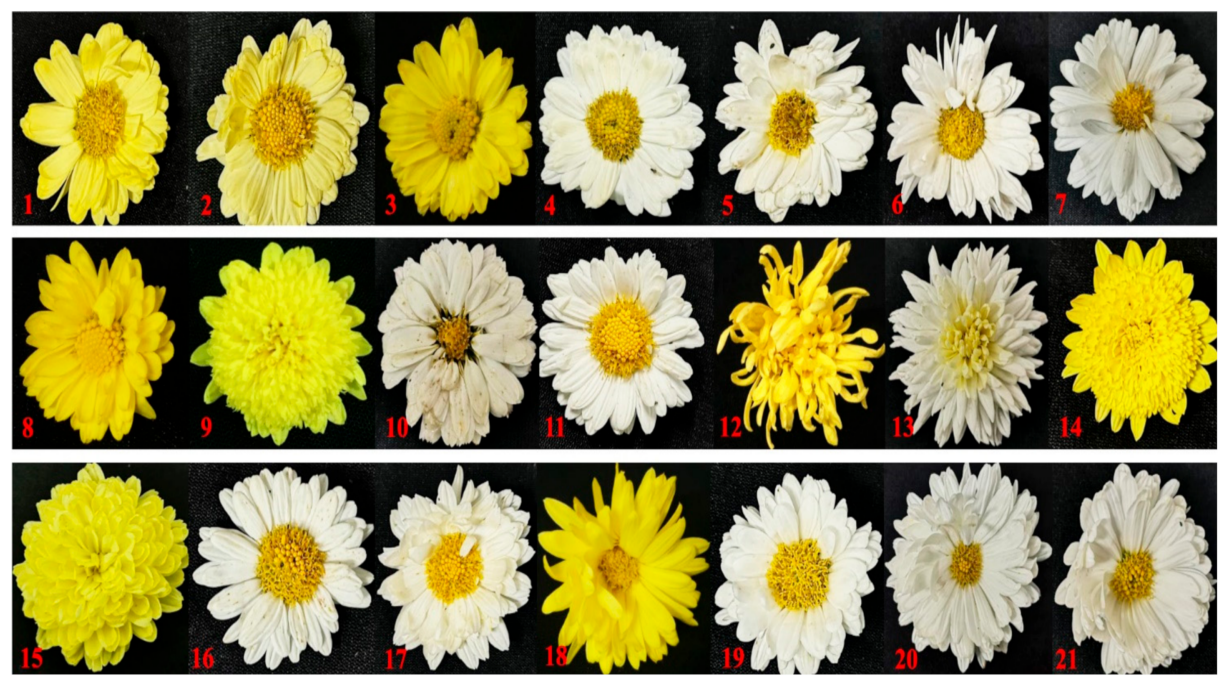

Figure 8. The flower morphology of 21 C. morifolium cultivars (1-21). Details of 21 C. morifolium cultivars are provided in Table 4. 
Table 4. Details of Chrysanthemum morifolium samples used in the study.

\begin{tabular}{|c|c|c|c|c|c|}
\hline Sample No. & Cultivar Name & Code & Material Types & Voucher Number & Location \\
\hline 1 & C. morifolium 'Jinju 1' & Jinju 1 & Hangju & CmTx0001 & Tongxiang, Zhejiang Province, China \\
\hline 2 & C. morifolium 'Jinju 2' & Jinju 2 & Hangju & CmTx0002 & Tongxiang, Zhejiang Province, China \\
\hline 3 & C. morifolium 'Jinju 3' & Jinju 3 & Hangju & CmTx0003 & Tongxiang, Zhejiang Province, China \\
\hline 4 & C. morifolium 'Xiaoyangju' & Xiaoyangju & Hangju & CmTx0004 & Tongxiang, Zhejiang Province, China \\
\hline 5 & C. morifolium 'Zaoxiaoyangju' & Zaoxiaoyangju & Hangju & CmTx0005 & Tongxiang, Zhejiang Province, China \\
\hline 6 & C. morifolium 'Dayangju' & Dayangju & Hangju & CmTx0006 & Tongxiang, Zhejiang Province, China \\
\hline 7 & C. morifolium 'Yizhongdabaiju' & Yizhongdabaiju & Hangju & CmTx0007 & Tongxiang, Zhejiang Province, China \\
\hline 8 & C. morifolium 'Xiaohuangju' & Xiaohuangju & Hangju & CmTx0008 & Tongxiang, Zhejiang Province, China \\
\hline 10 & C. morifolium 'Jiuyueju' & Jiuyueju & Hangju & CmTx0010 & Tongxiang, Zhejiang Province, China \\
\hline 11 & C. morifolium 'zhaohua 1 ' & Zhaohua 1 & Hangju & CmTx0011 & Tongxiang, Zhejiang Province, China \\
\hline 12 & C. morifolium 'Jinsihuangju' & Jinsihuangju & Jinsihuangju & $\mathrm{CmXs0001}$ & Xiushui, Jiangxi Province, China \\
\hline 13 & C. morifolium 'Daboju' & Daboju & Boju & CmBz0001 & Bozhou, An'hui Province, China \\
\hline 14 & C. morifolium 'Zaogongju' & Zaogongju & Gongju & $\mathrm{CmSx0001}$ & Shexian, An'hui Province, China \\
\hline 15 & C. morifolium 'Wuyuanhuangju' & Wuyuanhuangju & Wuyuanhuangju & CmWy0001 & Wuyuan, Jiangxi Province, China \\
\hline 16 & C. morifolium 'Xiaobaiju' & Xiaobaiju & Hangju & CmSy0001 & Sheyang, Jiangsu Province, China \\
\hline 17 & C. morifolium 'Machengju' & Machengju & Machengju & CmMc0001 & Macheng, Hubei Province, China \\
\hline 18 & C. morifolium 'Dahuangju' & Dahuangju & Hangju & CmSy0002 & Sheyang, Jiangsu Province, China \\
\hline 21 & C. morifolium 'Dabaiju' & Dabaiju & Hangju & CmSy0005 & Sheyang, Jiangsu Province, China \\
\hline
\end{tabular}


Table 5. List of C. morifolium 'Daboju' populations used for SCAR marker validation.

\begin{tabular}{llll}
\hline Number & Individual Numbers & Voucher Number & Location \\
\hline 1 & 10 & $\mathrm{CmBz0015}$ & Wuma, Bozhou, An'hui Province, China \\
2 & 12 & $\mathrm{CmBz0016}$ & Wuma, Bozhou, An'hui Province, China \\
3 & 11 & $\mathrm{CmBz0036}$ & Shatu, Bozhou, An'hui Province, China \\
4 & 8 & $\mathrm{CmBz0052}$ & Shuanggou, Bozhou, An'hui Province, China \\
5 & 13 & $\mathrm{CmBz0061}$ & Shuanggou, Bozhou, An'hui Province, China \\
6 & 8 & $\mathrm{CmBz0074}$ & Zhaoqiao, Bozhou, An'hui Province, China \\
7 & 10 & $\mathrm{CmTx0025}$ & Tongxiang, Zhejiang Province, China \\
8 & 9 & $\mathrm{CmTx0032}$ & Tongxiang, Zhejiang Province, China \\
9 & 10 & $\mathrm{CmPa0001}$ & Pan'an, Zhejiang Province, China \\
10 & 12 & $\mathrm{CmPa0013}$ & Pan'an, Zhejiang Province, China \\
\hline
\end{tabular}

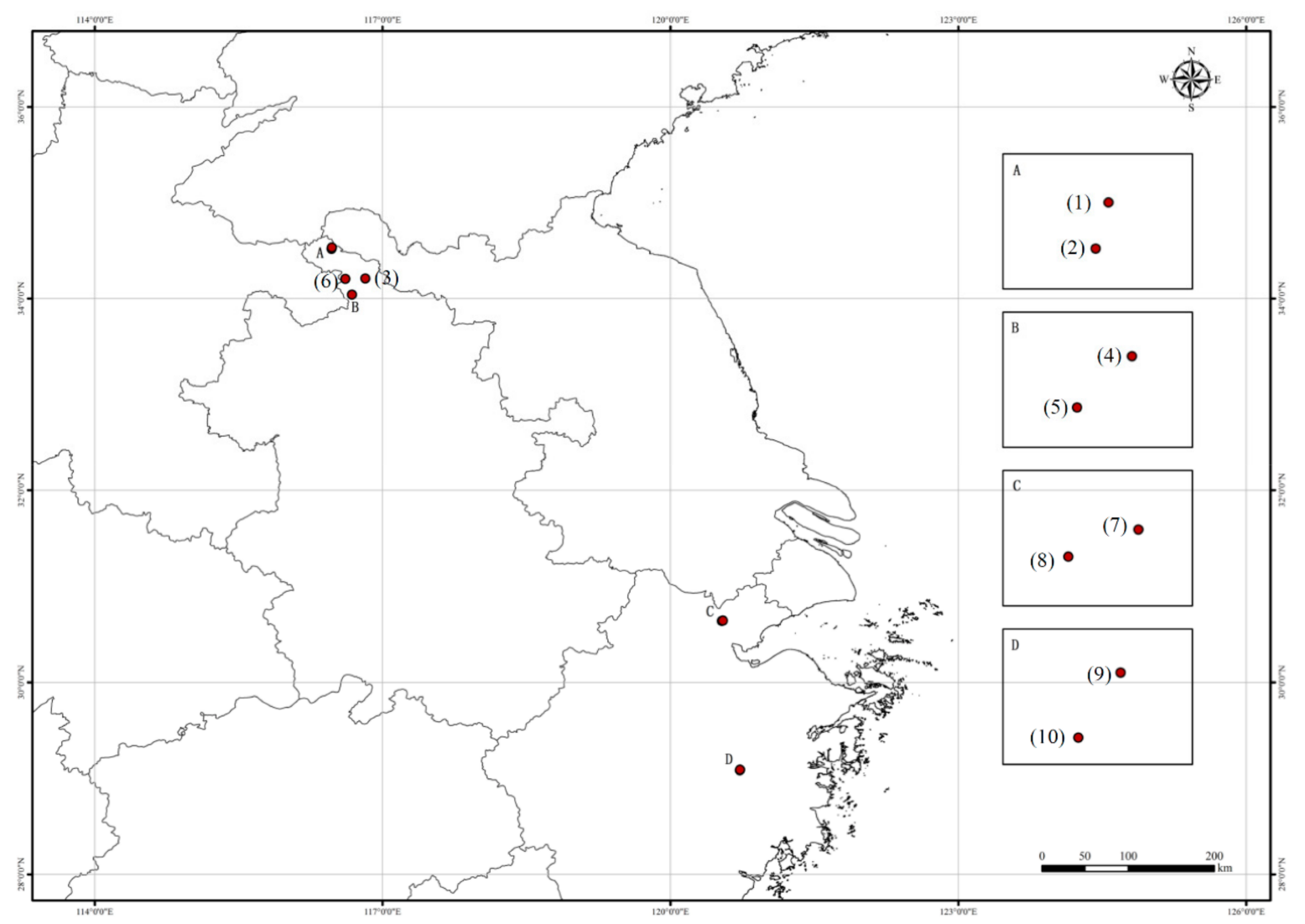

Figure 9. Sampling locations of 10 C. morifolium 'Daboju' populations. Numbers 1-10 are the same as those in Table 5.

\subsection{PCR Amplification with SCoT Primers}

Thirty-six PCR primers for SCoT analysis were selected from the study of Collard and MacKill [38]. SCoT-PCR was performed in $20 \mu \mathrm{L}$ reaction volumes containing $10 \mu \mathrm{L}$ of $2 \times$ EasyTaq PCR SuperMix (Beijing TransGen Biotech Co., Ltd., Beijing, China), $1 \mu \mathrm{L}$ of genomic DNA template (50 ng), $1 \mu \mathrm{L}$ of each primer $(10 \mu \mathrm{M})$, and $8 \mu \mathrm{L}$ of $\mathrm{ddH}_{2} \mathrm{O}$. The PCR reaction was performed as follows: $94{ }^{\circ} \mathrm{C}$ for $5 \mathrm{~min}, 35$ cycles of $94{ }^{\circ} \mathrm{C}$ for $1 \mathrm{~min}, 50-60{ }^{\circ} \mathrm{C}$ for $50 \mathrm{~s}$ (depending on the optimum annealing temperature of each primer), and $72{ }^{\circ} \mathrm{C}$ for $1.5 \mathrm{~min}$, followed by extension at $72{ }^{\circ} \mathrm{C}$ for $10 \mathrm{~min}$. The PCR products were analyzed by electrophoresis on $1.5 \%(w / v)$ agarose gels. The amplified DNA bands were stained with GelStain (Beijing TransGen Biotech Co., Ltd., Beijing, China) and the images photographed on a UV transilluminator. To check for reproducibility of results, PCR reactions were repeated at least three times. 


\subsection{Analysis of SCoT Profiles, and Selection of Specific SCoT Bands}

In order to count the number of primer-amplified loci and to evaluate the degree of polymorphism of primer-amplified DNA bands, the number of amplified bands was calculated by Quantity One software (Version 4.6.2, Bio-Rad Technical Service Department, USA) with manual correction. The bands that were reproducible and unambiguous were marked as ' 1 ' and the absence of a band at the same locus was scored as ' 0 '. Any DNA band present in a specific cultivar and absent in all the other cultivars at the same locus was defined as a cultivar-specific marker.

\subsection{Cloning and Sequencing of Specific SCoT Fragments}

A selected cultivar-specific band was extracted and purified from an agarose gel using a SanPrep Column DNA Gel Extraction Kit (Shanghai Sangon Biological Engineering Technology and Service Co. Ltd., Shanghai, China). The purified DNA fragment was cloned into the $\mathrm{pMD}^{\mathrm{TM}} 19-\mathrm{T}$ vector (Takara Co., Ltd., Beijing, China) according to the manufacturer's protocol, transformed into DH5 $\alpha$ Escherichia coli competent cells, and cultured at $37^{\circ} \mathrm{C}$ overnight. The recombinant plasmids were selected by colony PCR, and clones with correct-sized inserts were sequenced bidirectionally, using M13 universal primers by Shanghai Sunny Biotechnology Co. Ltd. (Shanghai, China).

\subsection{Sequence Data Analysis and SCAR Marker Development}

The online tool VecScreen (https: / / www.ncbi.nlm.nih.gov/tools/vecscreen/, accessed on 28 December 2021) was used to remove vector sequences from the obtained sequence, and the nucleotide database of the BLASTN program (https: / / blast.ncbi.nlm.nih.gov / Blast. cgi, accessed on 28 December 2021) was used to identify the similarities between sequences. Ultimately, the sequence obtained was submitted to the GenBank database (GenBank accession number: OL456174) [52]. The SCAR primer pair (named DBJF/DBJR) was designed based on the specific 385-bp nucleotide sequence of the 'Daboju'-specific SCoT36385 amplicon, obtained using Primer Premier 5 software [53] (Table 2), and synthesized by Shanghai Sangon Biological Engineering Technology and Service Co. Ltd., Shanghai, China.

\subsection{Specificity of the SCAR Marker}

First, the specificity of the SCAR marker was evaluated by PCR amplification of the DNA of the 21 medicinal chrysanthemum cultivars (Table 4). Furthermore, 10 selected 'Daboju' populations were used to further validate the SCAR marker developed (Table 5). The high-specificity SCAR marker could detect the 360-bp amplification bands only in 'Daboju' samples, but not in the other chrysanthemum cultivar samples tested. After preliminary screening, the optimum annealing temperature for the SCAR-PCR reaction was determined to be $62^{\circ} \mathrm{C}$. SCAR-PCR was performed in a $20 \mu \mathrm{L}$ reaction mixture containing $10 \mu \mathrm{L}$ of $2 \times$ EasyTaq PCR SuperMix (Beijing TransGen Biotech Co., Ltd., Beijing, China), $1 \mu \mathrm{L}$ of genomic DNA template (50 ng), $1 \mu \mathrm{L}$ of forward primer $(10 \mu \mathrm{M}), 1 \mu \mathrm{L}$ of reverse primer $(10 \mu \mathrm{M})$, and $7 \mu \mathrm{L}$ of $\mathrm{ddH}_{2} \mathrm{O}$. PCR reaction was performed under the following conditions: $94{ }^{\circ} \mathrm{C}$ for $5 \mathrm{~min}, 35 \mathrm{cycles}$ of $94{ }^{\circ} \mathrm{C}$ for $1 \mathrm{~min}, 62{ }^{\circ} \mathrm{C}$ for $50 \mathrm{~s}$, and $72{ }^{\circ} \mathrm{C}$ for $1.5 \mathrm{~min}$, followed by $72{ }^{\circ} \mathrm{C}$ extension for $10 \mathrm{~min}$. The conditions of agarose gel $(1.5 \%, w / v)$ electrophoresis were the same as described above.

\subsection{Sensitivity and Application of the SCAR Marker}

The sensitivity of the SCAR marker (DBJF/DBJR) was tested with a dilution series of purified 'Daboju' genomic DNA: 50 ng, 40 ng, 30 ng, 20 ng, 10 ng, 100 pg, and 10 pg in $20 \mu \mathrm{L}$ of PCR reaction mixture. To further test the applicability of the SCAR marker primer pairs (DBJF/DBJR) in practice, genomic DNA of 'Xiaoyangju,' 'Zaoxiaoyangju,' 'Dayangju,' 'Machengju,' and 'Hongxinju,' the flowers of which are similar to those of 'Daboju' (Figure 8), were utilized to simulate different adulterations of 'Daboju' (Table 4). 
The composition of the PCR reaction mixture, and conditions of the PCR amplification program and of agarose gel $(1.5 \%, \mathrm{w} / \mathrm{v})$ electrophoresis were the same as described above.

\section{Conclusions}

A 'Daboju'-specific DNA fragment, SCoT36-385, was obtained, and a reliable and reproducible SCAR marker primer pair (DBJF/DBJR) was subsequently developed from this fragment for the identification of genuine samples of 'Daboju'. The SCAR marker DBJF/DBJR could specifically identify genetic material of 'Daboju' and distinguish it from those of other Chrysanthemum cultivars. Thus, the development of these efficient SCAR markers for 'Daboju' will greatly contribute to the conservation and rational utilization of this important Chrysanthemum plant resource.

Author Contributions: S.F. and H.W. conceived and designed the experiments, participated in the analysis and drafted the manuscript; Y.C., Y.G. and Z.Z. performed the experiments; Y.W., H.L., Y.M. and Y.L. performed the statistical analysis; S.F., Y.C. and H.W. collected plant samples. All authors have read and agreed to the published version of the manuscript.

Funding: Our work was funded by the Zhejiang Provincial Natural Science Foundation of China (LY20H280012); the Zhejiang Provincial Key Research \& Development Project Grants (2018C02030); the National Natural Science Foundation of China (31970346); the key project at the central government level for the ability establishment of sustainable use for valuable Chinese medicine resources (2060302); and the Hangzhou Scientific and Technological Program of China (20191203B02).

Data Availability Statement: All data are included in the manuscript, and the specific DNA fragment, namely SCoT36-385, has been deposited in GenBank (GenBank accession number: OL456174).

Acknowledgments: Thanks to the staff of the Tongxiang Chrysanthemum Experimental Field of the Zhejiang Provincial Key Laboratory for Genetic Improvement and Quality Control of Medicinal Plants, for helping to manage and collect experimental materials.

Conflicts of Interest: The authors declare no conflict of interest.

\section{References}

1. Gong, J.; Chu, B.; Gong, L.; Fang, Z.; Zhang, X.; Qiu, S.; Wang, J.; Xiang, Y.; Xiao, G.; Yuan, H.; et al. Comparison of Phenolic Compounds and the Antioxidant Activities of Fifteen Chrysanthemum morifolium Ramat cv. 'Hangbaiju' in China. Antioxidants 2019, 8, 325. [CrossRef] [PubMed]

2. Ma, Y.P.; Zhao, L.; Zhang, W.J.; Zhang, Y.H.; Xing, X.; Duan, X.X.; Hu, J.; Harris, A.J.; Liu, P.L.; Dai, S.L.; et al. Origins of cultivars of Chrysanthemum-Evidence from the chloroplast genome and nuclear LFY gene. J. Syst. Evol. 2020, 58, 925-944. [CrossRef]

3. National Pharmacopoeia Commission. Pharmacopoeia of the People's Republic of China; China Medical Science and Technology Press: Bejing, China, 2015.

4. Chang, T.L.; Liou, P.S.; Cheng, P.Y.; Chang, H.N.; Tsai, P.J. Borneol and Luteolin from Chrysanthemum morifolium Regulate Ubiquitin Signal Degradation. J. Agric. Food Chem. 2018, 66, 8280-8290. [CrossRef] [PubMed]

5. Wang, Y.; Xu, Z.; Wen, X.; Li, M.; Pang, S.; Huang, Y.; Ni, Y. The formation and bioactivities of green substances in Chrysanthemum morifolium tea. Food Chem. 2019, 286, 268-274. [CrossRef] [PubMed]

6. Liu, G.; Zheng, Q.; Pan, K.; Xu, X. Protective effect of Chrysanthemum morifolium Ramat. ethanol extract on lipopolysaccharide induced acute lung injury in mice. BMC Complementary Med. Ther. 2020, 20, 235. [CrossRef] [PubMed]

7. Feng, S.; He, R.; Lu, J.; Jiang, M.; Shen, X.; Jiang, Y.; Wang, Z.; Wang, H. Development of SSR Markers and Assessment of Genetic Diversity in Medicinal Chrysanthemum morifolium Cultivars. Front. Genet. 2016, 7, 113. [CrossRef] [PubMed]

8. Hodaei, M.; Rahimmalek, M.; Arzani, A. Variation in bioactive compounds, antioxidant and antibacterial activity of Iranian Chrysanthemum morifolium cultivars and determination of major polyphenolic compounds based on HPLC analysis. J. Food Sci. Technol. 2021, 58, 1538-1548. [CrossRef] [PubMed]

9. Zhang, W.; Jiang, Y.; Chen, S.; Chen, F.; Chen, F. Concentration-dependent emission of floral scent terpenoids from diverse cultivars of Chrysanthemum morifolium and their wild relatives. Plant Sci. 2021, 309, 110959. [CrossRef]

10. Feng, S.G.; He, R.F.; Jiang, M.Y.; Lu, J.J; Shen, X.X.; Liu, J.J.; Wang, Z.A.; Wang, H.Z. Genetic diversity and relationships of medicinal Chrysanthemum morifolium revealed by start codon targeted (SCoT) markers. Sci. Hortic. 2016, 201, 118-123. [CrossRef]

11. Zhang, W.; Zuo, Y.; Xu, F.; Wang, T.; Liu, J.; Wu, D. Correction to: Study of the mechanism of change in flavonoid composition in the processing of Chrysanthemum morifolium (Ramat.) Tzvel. 'Boju'. BMC Chem. 2020, 14, 16. [CrossRef] [PubMed]

12. Peng, A.; Lin, L.; Zhao, M.; Sun, B. Identifying mechanisms underlying the amelioration effect of Chrysanthemum morifolium Ramat. 'Boju' extract on hyperuricemia using biochemical characterization and UPLC-ESI-QTOF/MS-based metabolomics. Food Funct. 2019, 10, 8042-8055. [CrossRef] [PubMed] 
13. Peng, A.; Lin, L.; Zhao, M. Screening of key flavonoids and monoterpenoids for xanthine oxidase inhibitory activity-oriented quality control of Chrysanthemum morifolium Ramat. 'Boju' based on spectrum-effect relationship coupled with UPLC-TOF-MS and HS-SPME-GC/MS. Food Res. Int. 2020, 137, 109448. [CrossRef]

14. Zhao, H.; Chen, S.; Tang, F.; Jiang, J.; Li, C.; Miao, H.; Chen, F.; Fang, W.; Guo, W. Morphological characteristics and chromosome behaviour in F1, F2 and BC1 progenies between Chrysanthemum x morifolium and Ajania pacifica. Genetika 2012, 48, 951-961. [CrossRef] [PubMed]

15. Fei, J.; Tan, S.; Zhang, F.; Hua, L.; Liao, Y.; Fang, W.; Chen, F.; Teng, N. Erratum to: Morphological and physiological differences between dehiscent and indehiscent anthers of Chrysanthemum morifolium. J. Plant. Res. 2016, 129, 1083. [CrossRef] [PubMed]

16. Wang, F.; Zhong, X.; Huang, L.; Fang, W.; Chen, F.; Teng, N. Cellular and molecular characteristics of pollen abortion in chrysanthemum cv. Kingfisher. Plant. Mol. Biol. 2018, 98, 233-247. [CrossRef]

17. Yao, X.; Chu, J.Z.; Ma, C.H.; Si, C.; Li, J.G.; Shi, X.F.; Liu, C.N. Biochemical traits and proteomic changes in postharvest flowers of medicinal chrysanthemum exposed to enhanced UV-B radiation. J. Photochem. Photobiol. B 2015, 149, 272-279. [CrossRef]

18. Guan, C.F.; Chachar, S.; Zhang, P.X.; Hu, C.Q.; Wang, R.Z.; Yang, Y. Inter- and intra-specific genetic diversity in Diospyros using SCoT and IRAP markers. Hortic. Plant. J. 2020, 6, 71-80. [CrossRef]

19. Fu, Y.R.; Liu, F.L.; Li, S.; Tian, D.K.; Dong, L.; Chen, Y.C.; Su, Y. Genetic diversity of the wild Asian lotus (Nelumbo nucifera) from Northern China. Hortic Plant. J. 2021, 7, 488-500. [CrossRef]

20. Shao, Q.S.; Guo, Q.S.; Deng, Y.M.; Guo, H.P. A comparative analysis of genetic diversity in medicinal Chrysanthemum morifolium based on morphology, ISSR and SRAP markers. Biochem. Syst. Ecol. 2010, 38, 1160-1169. [CrossRef]

21. Hodaei, M.; Rahimmalek, M.; Arzani, A. Genetic diversity of Iranian Chrysanthemum morifolium cultivars using morphological traits and sequence-related amplified polymorphism (SRAP) markers. Hortic. Environ. Biotechnol. 2019, 60, 753-765. [CrossRef]

22. Roein, Z.; Asil, M.H.; Sabouri, A.; Dadras, A.R. Genetic structure of Chrysanthemum genotypes from Iran assessed by AFLP markers and phenotypic traits. Plant Syst. Evol. 2014, 300, 493-503. [CrossRef]

23. Samarina, L.S.; Malyarovskaya, V.I.; Reim, S.; Yakushina, L.G.; Koninskaya, N.G.; Klemeshova, K.V.; Shkhalakhova, R.M.; Matskiv, A.O.; Shurkina, E.S.; Gabueva, T.Y.; et al. Transferability of ISSR, SCoT and SSR markers for Chrysanthemum $x$ morifolium Ramat and genetic relationships among commercial Russian cultivars. Plants 2021, 10, 1302. [CrossRef] [PubMed]

24. Zhang, F.; Chen, S.M.; Chen, F.D.; Fang, W.M.; Li, F.T. A preliminary genetic linkage map of chrysanthemum (Chrysanthemum morifolium) cultivars using RAPD, ISSR and AFLP markers. Sci. Hortic. 2010, 125, 422-428. [CrossRef]

25. Zhang, F.; Chen, S.M.; Chen, F.D.; Fang, W.M.; Chen, Y.; Li, F.T. SRAP-based mapping and QTL detection for inflorescence-related traits in chrysanthemum (Dendranthema morifolium). Mol. Breed. 2011, 27, 11-23. [CrossRef]

26. Fan, M.; Gao, Y.; Wu, Z.; Zhang, Q. Linkage map development by EST-SSR markers and QTL analysis for inflorescence and leaf traits in chrysanthemum (Chrysanthemum morifolium Ramat.). Plants 2020, 9, 1342. [CrossRef]

27. Fu, X.; Su, J.S.; Yu, K.L.; Cai, Y.F.; Zhang, F.; Chen, S.M.; Fang, W.M.; Fadi, C.; Guan, Z.Y. Genetic variation and association mapping of aphid (Macrosiphoniella sanbourni) resistance in chrysanthemum (Chrysanthemum morifolium Ramat.). Euphytica 2018, 214, 21. [CrossRef]

28. Jha, S.R.; Naz, R.; Asif, A.; Okla, M.K.; Soufan, W.; Al-Ghamdi, A.A.; Ahmad, A. Development of an in vitro propagation protocol and a sequence characterized amplified region (SCAR) marker of Viola serpens Wall. ex Ging. Plants 2020, 9, 246. [CrossRef]

29. Feng, S.G.; Zhu, Y.J.; Yu, C.L.; Jiao, K.L.; Jiang, M.Y.; Lu, J.J.; Shen, C.J.; Ying, Q.C.; Wang, H.Z. Development of species-specific SCAR markers, based on a SCoT analysis, to authenticate Physalis (Solanaceae) species. Front. Genet. 2018, 9, 113. [CrossRef]

30. Marieschi, M.; Torelli, A.; Beghe, D.; Bruni, R. Authentication of Punica granatum L.: Development of SCAR markers for the detection of 10 fruits potentially used in economically motivated adulteration. Food Chem. 2016, 202, 438-444. [CrossRef]

31. Ravi, D.; Siril, E.A.; Nair, B.R. SCAR marker development for the identification of elite germplasm of Moringa oleifera Lam.-a never die plant. Plant Mol. Biol. Report. 2021, 39, 850-861. [CrossRef]

32. Cunha, J.T.; Ribeiro, T.I.B.; Rocha, J.B.; Nunes, J.; Teixeira, J.A.; Domingues, L. RAPD and SCAR markers as potential tools for detection of milk origin in dairy products: Adulterant sheep breeds in Serra da Estrela cheese production. Food Chem. 2016, 211, 631-636. [CrossRef]

33. Kumar, A.; Rodrigues, V.; Mishra, P.; Baskaran, K.; Shukla, A.K.; Shasany, A.K.; Sundaresan, V. ISSR-derived species-specific SCAR marker for rapid and accurate authentication of Ocimum tenuiflorum L. Planta Med. 2018, 84, 117-122. [CrossRef] [PubMed]

34. Roy, N.S.; Park, K.C.; Lee, S.I.; Im, M.J.; Ramekar, R.V.; Kim, N.S. Development of CACTA transposon derived SCAR markers and their use in population structure analysis in Zea mays. Genetica 2018, 146, 1-12. [CrossRef] [PubMed]

35. Xu, Y.X.; Shen, S.Y.; Chen, W.; Chen, L. Analysis of Genetic Diversity and development of a SCAR Marker for green tea (Camellia sinensis) cultivars in Zhejiang Province: The most famous green tea-producing area in China. Biochem. Genet. 2019, 57, 555-570. [CrossRef]

36. Zheng, K.; Cai, Y.; Chen, W.; Gao, Y.; Jin, J.; Wang, H.; Feng, S.; Lu, J. Development, identification, and application of a germplasm specific SCAR Marker for Dendrobium officinale Kimura et Migo. Front. Plant Sci. 2021, 12, 669458. [CrossRef] [PubMed]

37. Seethapathy, G.S.; Balasubramani, S.P.; Venkatasubramanian, P. nrDNA ITS sequence based SCAR marker to authenticate Aconitum heterophyllum and Cyperus rotundus in Ayurvedic raw drug source and prepared herbal products. Food Chem. 2014, 145, 1015-1020. [CrossRef] [PubMed]

38. Collard, B.C.Y.; Mackill, D.J. Start codon targeted (SCOT) polymorphism: A simple, novel DNA marker technique for generating gene-targeted markers in plants. Plant Mol. Biol. Report. 2009, 27, 86-93. [CrossRef] 
39. Mulpuri, S.; Muddanuru, T.; Francis, G. Start codon targeted (SCoT) polymorphism in toxic and non-toxic accessions of Jatropha curcas L. and development of a codominant SCAR marker. Plant Sci. 2013, 207, 117-127. [CrossRef] [PubMed]

40. Kumar, S.; Kumar, M.; Yadav, H.K.; Sharma, S.; Kumar, S. Genetic diversity and population structure analysis of Chrysanthemum (Dendranthema grandiflora Tzvelev) germplasm based on RAPD markers. J. Environ. Biol. 2017, 38, 457-464. [CrossRef]

41. Luo, C.; Chen, D.L.; Cheng, X.; Liu, H.; Li, Y.H.; Huang, C.L. SSR analysis of genetic relationship and classification in chrysanthemum germplasm collection. Hortic. Plant J. 2018, 4, 73-82. [CrossRef]

42. Zhang, Y.M.; Shen, X.L.; Sun, X.Q.; Liu, J.; Xia, Y.F.; Zou, X.; Hang, Y.Y. Molecular distinguishment of Trapa natans L. varieties in Taihu Lake region of China and development of a RAPD-SCAR marker for authentication of Heshangling. Hortscience 2019, 54, 1319-1323. [CrossRef]

43. Liu, X.; Cheng, J.; Mei, Z.; Wei, C.; Khan, M.A.; Peng, J.; Fu, J. SCAR marker for identification and discrimination of specific medicinal Lycium chinense Miller from Lycium species from ramp-PCR RAPD fragments. 3 Biotech 2020, 10, 334. [CrossRef] [PubMed]

44. Torelli, A.; Marieschi, M.; Bruni, R. Authentication of saffron (Crocus sativus L.) in different processed, retail products by means of SCAR markers. Food Control 2014, 36, 126-131. [CrossRef]

45. Jiang, Q.T.; Liu, L.; Xiao, B.Y.; Li, W.L.; Luo, H.M.; Nie, P.; Ding, Y.; Li, J.; Li, W.Z. Panax ginseng-specific sequence characterized amplified region (SCAR) marker for testing medicinal products. J. Cent. South Univ. 2018, 25, 1052-1062. [CrossRef]

46. Rajesh, M.K.; Sabana, A.A.; Rachana, K.E.; Rahman, S.; Ananda, K.S.; Karun, A. Development of a SCoT-derived SCAR marker associated with tall-type palm trait in arecanut and its utilization in hybrid (dwarf $\mathrm{x}$ tall) authentication. Indian J. Genet. Pl. Br. 2016, 76, 119-122. [CrossRef]

47. Li, Q.G.; Mo, J.M.; Wu, W.R.; Yang, J.; Li, J.J.; Lai, T.X.; Ou, Z.L.; Qiu, Z.W.; Guan, S.X.; Liao, J.J. Genetic diversity, population structure and identification of Dendrobium cultivars with high polysaccharide contents using SCoT, SCAR and nested PCR markers. Genet. Resour. Crop Ev. 2019, 66, 71-88. [CrossRef]

48. Li, X.; Yang, Y.; Henry, R.J.; Rossetto, M.; Wang, Y.; Chen, S. Plant DNA barcoding: From gene to genome. Biol. Rev. Camb. Philos. Soc. 2015, 90, 157-166. [CrossRef]

49. Feng, S.; Jiang, M.; Shi, Y.; Jiao, K.; Shen, C.; Lu, J.; Ying, Q.; Wang, H. Application of the ribosomal DNA ITS2 region of Physalis (Solanaceae): DNA barcoding and phylogenetic study. Front. Plant. Sci. 2016, 7, 1047. [CrossRef]

50. Veldman, S.; Ju, Y.; Otieno, J.N.; Abihudi, S.; Posthouwer, C.; Gravendeel, B.; van Andel, T.R.; de Boer, H.J. DNA barcoding augments conventional methods for identification of medicinal plant species traded at Tanzanian markets. J. Ethnopharmacol 2020, 250, 112495. [CrossRef]

51. Thakur, V.V.; Tripathi, N.; Tiwari, S. DNA barcoding of some medicinally important plant species of Lamiaceae family in India. Mol. Biol. Rep. 2021, 48, 3097-3106. [CrossRef] [PubMed]

52. Sayers, E.W.; Cavanaugh, M.; Clark, K.; Pruitt, K.D.; Schoch, C.L.; Sherry, S.T.; Karsch-Mizrachi, I. GenBank. Nucleic Acids Res. 2021, 49 (Suppl. D1), D92-D96. [CrossRef] [PubMed]

53. Lalitha, S. Primer premier 5. Biotech Softw. Internet Rep. Comput. Softw. J. Sci. 2000, 1, 270-272. [CrossRef] 